\title{
International Primary Care Respiratory Group (IPCRG) Guidelines: Management of allergic rhinitis
}

\author{
David Price $^{\mathrm{a}, *}$, Christine Bond ${ }^{\mathrm{a}}$, Jacques Bouchard ${ }^{\mathrm{b}}$, Rui Costa ${ }^{\mathrm{c}}$, \\ Joseph Keenan ${ }^{d}$, Mark L. Levy ${ }^{e}$, Mari Orru ${ }^{f}$, Dermot Ryan ${ }^{a}$, \\ Samantha Walker ${ }^{\mathrm{g}}$, Margaret Watson ${ }^{a}$
}

\begin{abstract}
a Department of General Practice, University of Aberdeen, Foresterhill Health Centre, Westburn Road, Aberdeen, AB25 2AY, UK

${ }^{\mathrm{b}}$ Respiratory Dept, St. Josephs Hospital, 515 Rue St. Etienne, La Malbaie, Quebec, Canada

c Sãvida Medicina Apoiada, SA, Rua do Bolhão 109, 4000-112 Porto, Portugal

d University of Minnesota Medical School, 240 Williamson Hall, 231 Pilsbury Drive S.E. Minpecipolis, MN 55455-0213, USA

e Division of Community Health Sciences: GP Section, University df Edint|irgl, , 20 West Richmond Street, Edinburgh, UK

f Pharm D, Cagliari, Italy

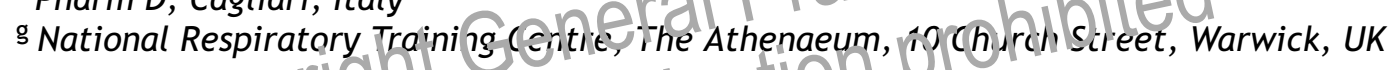

Received 1November 2005; acteited 8 / /
\end{abstract}

\section{KEYWORDS \\ Guideline; \\ Primary care; \\ General practice; \\ Rhinitis; \\ Classification; \\ Management; \\ Treatment}

\begin{abstract}
Summary The association between the upper and lower airways has been recognised for almost 2000 years. Epidemiological data suggest that most asthma patients also suffer from allergic rhinitis, and that both diseases share similar trigger factors and pathophysiology. This IPCRG Guideline on the management of rhinitis in primary care is fully consistent with the ARIA guidelines. It highlights the treatment goals and the classification of the condition according to symptom frequency (intermittent or persistent) and severity (mild or moderate-severe). It covers the need for allergen avoidance, pharmacologic therapy including immunotherapy, alternative therapies, management of ocular symptoms, the management of coexisting allergic rhinitis and asthma, and the need for follow-up and ongoing care for patients with rhinitis.

(C) 2005 General Practice Airways Group. Published by Elsevier Ltd. All rights reserved.
\end{abstract}

\section{Background}

Primary care physicians treat the majority of patients with respiratory diseases. However, in most countries, specific primary care guidelines
* Corresponding author. Tel.: +44 (0) 1224554588.

E-mail address: David@respiratoryresearch.org (D. Price). 
are not available. Since clinical management which follows evidence-based guidelines yields better results for patients, it is important to have access to primary care guidelines which are specifically relevant to, and provided by, primary care. The International Primary Care Respiratory Group (IPCRG) asked primary care experts from several countries to develop primary care guidelines for the diagnosis and treatment of asthma, chronic obstructive pulmonary disease (COPD) and rhinitis. A brief summary of the expert report (which took three years to complete) was published as a handbook [1] in 2005.

This paper is devoted to the management of rhinitis in primary care and is specifically written for primary care health professionals. In addition to this rhinitis section, the IPCRG guidelines consist of papers on the diagnosis of respiratory disease [2], and the management of COPD [3] and asthma [4]. For the specific purpose of ranking the evidence in each of these publications, we have used the so-called Three Star System of the Royal College of General Practitioners [5] in order to score the evidence of the statements made (see box).
[8]. In 2002 the Global Initiative for Asthma guidelines (GINA) discussed the same issues as the UK asthma guidelines but also added that treatment of rhinitis may improve asthma outcomes [9]. This major change followed a World Health Organization initiative - publication of Allergic Rhinitis and its Impact on Asthma (ARIA), a comprehensive review of the impact of allergic rhinitis on asthma [10], and evidence has evolved even further since its publication.

\section{Evidence that influenced guidelines}

Asthma and allergic rhinitis (AR) frequently coexist with epidemiological data suggesting that most asthma patients also suffer from allergic rhinitis [11]. We also see similar trends in asthma and AR prevalence around the world using objective epidemiological instruments [12]. Both diseases share similar triggers and similar pathophysiology characterised by similar inflammatory cell infiltrates [13]. It has also been

\section{Three Star System of the Royal College of General Practitioners}

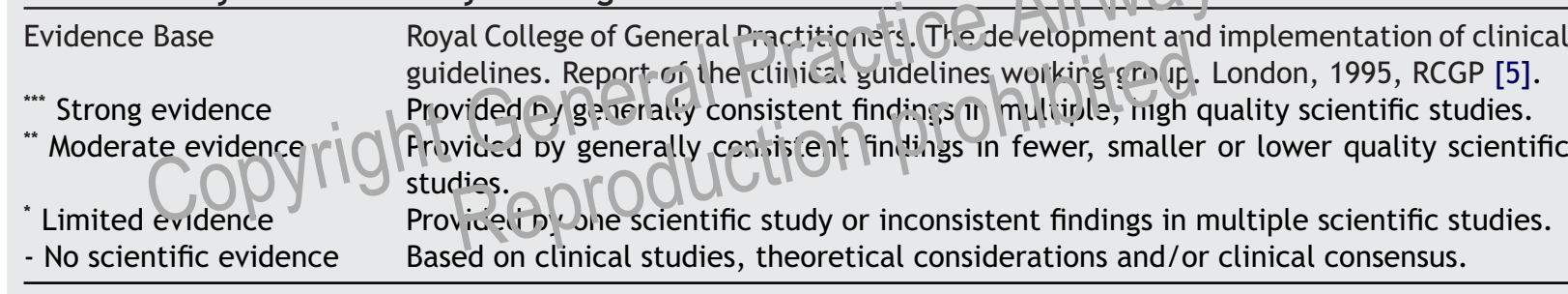

\section{Introduction}

The association between the upper and lower airways has been recognized for almost two millennia, ever since Galen recommended in 200AD that purging the nostrils of secretions would relieve the lungs. By the late $19^{\text {th }}$ century Charles Blackley had linked hay fever and asthma [6].

It is therefore striking that until recently asthma guidelines have referred minimally to the importance of rhinitis in patients with asthma. The 1997 UK asthma guidelines did not even mention the word rhinitis [7]. The updated 2003 UK guidelines mention its role in helping to make a diagnosis of asthma, state that immunotherapy for rhinitis sufferers might reduce the rate of onset of asthma, and state that many patients with asthma may have rhinitis but that there is no evidence that rhinitis treatment improves asthma outcomes found that the degree of inflammation in asthma correlates highly with the level of inflammation in the nose [13], that allergen challenge in the nose leads to hyperresponsiveness in the lungs [14] and that allergen challenge in the lung leads to inflammation in the nose [15]. More important than the simple association between asthma and rhinitis is the finding that clinically diagnosed allergic rhinitis is associated with significantly worse asthma control; studies from a recent analysis of patients in a General Practice database in the UK found that children with physician-diagnosed AR were more than twice as likely to be hospitalised for asthma as those without AR, and that adults with AR were $50 \%$ more likely be admitted for asthma $[16,17]$.

As a result the ARIA guidelines recommend that patients with asthma be evaluated for allergic rhinitis and vice versa. The guidelines support a combined approach to treating both 
conditions [10], an approach based on: education and allergen avoidance; pharmacotherapy for allergic rhinitis along with asthma therapy; specific immunotherapy; and rarely surgery.

\section{Treatment Goals}

Goals for the treatment of rhinitis assume accurate diagnosis and assessment of severity as well as any link with asthma in an individual patient. Goals include:

- Unimpaired sleep

- Ability to undertake normal daily activities, including work and school attendance, without limitation or impairment, and the ability to participate fully in sport and leisure activities

\section{Allergen and pollutant avoidance}

Whilst removal of allergens lessens the severity of the allergic disorder, it is not always possible to implement fully adequate allergen avoidance; as a result no truly convincing trial results have been achieved [18]. Allergen sensitivity should be documented before recommending avoidance measures that may have considerable lifestyle implications [19]*.

Patients with allergic rhinitis should be advised not to smoke since this may worsen asthma and rhinitis and reduce treatment efficacy, and to limit their exposure to environmental tobacco smoke as much as possible. Pharmacotherapy and support for smoking cessation should be provided when appropriate.

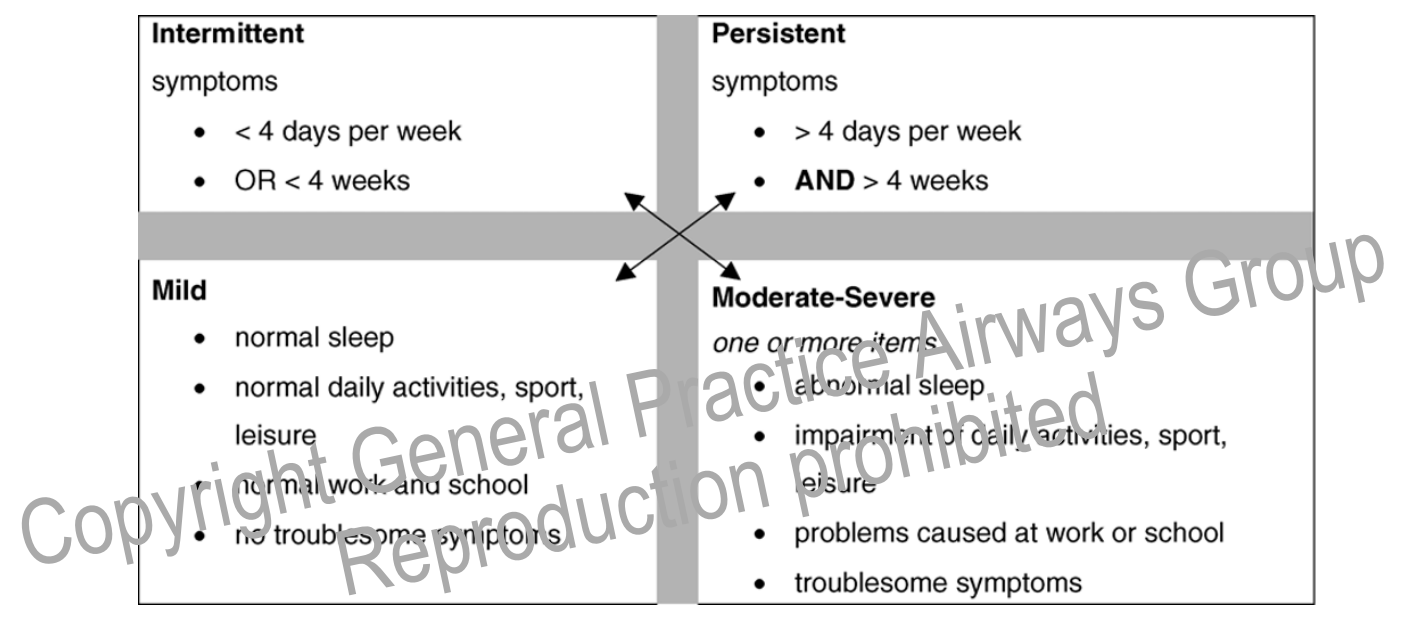

Figure 1 Classification of Allergic Rhinitis.

- No troublesome symptoms

- No or minimal side-effects of rhinitis treatment

\section{Classification}

The classification of allergic rhinitis depends on the duration of symptoms ("Intermittent" or "Persistent") together with the severity and effect on the patient's daily life ("Mild" or "ModerateSevere") (Figure 1) [10]. The classification of rhinitis determines the treatment needed. Those with mild disease which is intermittent in nature require less intensive therapy [10].

\section{Pharmacologic therapy}

Pharmacologic treatment of allergic rhinitis depends on both the classification of severity and the individual patient's symptoms as described in Figure 1. Table 1 provides treatment options based on the severity of the disease. The choice of pharmacologic treatment may be individualized based on the patient's particular combination of symptoms. Medications for allergic rhinitis have no long-lasting effect following discontinuation. Therefore, in persistent disease, maintenance treatment is required. Table 2 provides detailed notes on the treatments available in rhinitis. 
Table 1 Allergic Rhinitis Therapy by Classification of disease severity

\begin{tabular}{ll}
\hline Mild Intermittent Allergic Rhinitis & Mild Persistent Allergic Rhinitis \\
\hline - Oral H1-blocker & - Oral H1-blocker \\
- Intranasal H1-blocker & - Intranasal H1-blocker AND/OR \\
- Decongestant AND/OR & - Decongestant \\
- Intranasal saline & - Intranasal glucocorticosteroid \\
& - Intranasal saline \\
& - Cromone \\
& - Antileukotriene (preferred in patients with coexisting asthma) \\
& - Consider specialist referral for specific immunotherapy
\end{tabular}

Review patient after 2-4 weeks.

If improved: Consider stepping down therapy.

If failure: Review diagnosis, review compliance, query infections and other causes, then consider trial of different treatment option or step up therapy (See Moderate/Severe Intermittent Allergic Rhinitis below).
Review patient after 2-4 weeks.

If improved: Continue treatment for at least 1 month after symptoms resolve. Consider stepping down dose.

If failure: Review diagnosis, review compliance, query infections and other causes, then consider trial of different treatment option or step up therapy (See Moderate/Severe Persistent Allergic Rhinitis below).

\section{Moderate/Severe Intermittent Allergic Rhinitis \\ - Oral H1-blocker \\ - Intranasal H1-blocker AND/OR \\ - Decongestant \\ - Intranasal saline \\ - Intranasal glucocorticosteroid \\ - Cromone \\ - Antileukotriene (preferred in patients with coexisting asthma) \\ - Consider specialist referral for sperifiic immunotherapy
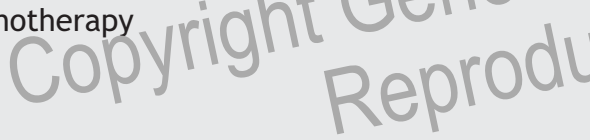

Review patient after $2-4$ weeks.

If improved: Consider stepping down therapy.

If failure: Review diagnosis, review compliance, query infections and other causes, then consider trial of different treatment option or specialist referral.

\section{Moderate/Severe Persistent Allergic Rhinitis}

- Intranasal glucocorticosteroid

- Oral H1-blocker

- Decongestant

- Intranasal saline

- Antileukotriene (preferred in natie ass vitr coxlscing asthma) - Consider specialist réferlal for s.ecific immunotherapy Roview pa ient arter $2-4$ weeks.

If improved continule teatrient for at least 1 month after c)

If :ailure: Review diagnosis, review compliance, query infections and other causes, then choose one or more of the following options:

Review patient after 2-4 weeks.

If improved: Continue treatment for at least 1 month after symptoms resolve. Consider stepping down dose.

If failure: Review diagnosis, review compliance, query infections and other causes, then:

- Increase nasal steroid dose, consider trial of different treatment option, or consider specialist referral

- If itch/sneeze: add H1-blocker

- If rhinorrhea: add ipratropium

- If blockage: Add decongestant or short course of oral steroids.

- If failure: consider specialist referral (including surgery).

NOTES: Treatment options in the table above are given in increasing order of cost. Relative medication costs may vary from country to country. The choice among treatment options is likely to depend somewhat on local availability of drugs, national formularies, and cost. 
Table 2 Allergic Rhinitis Treatments available

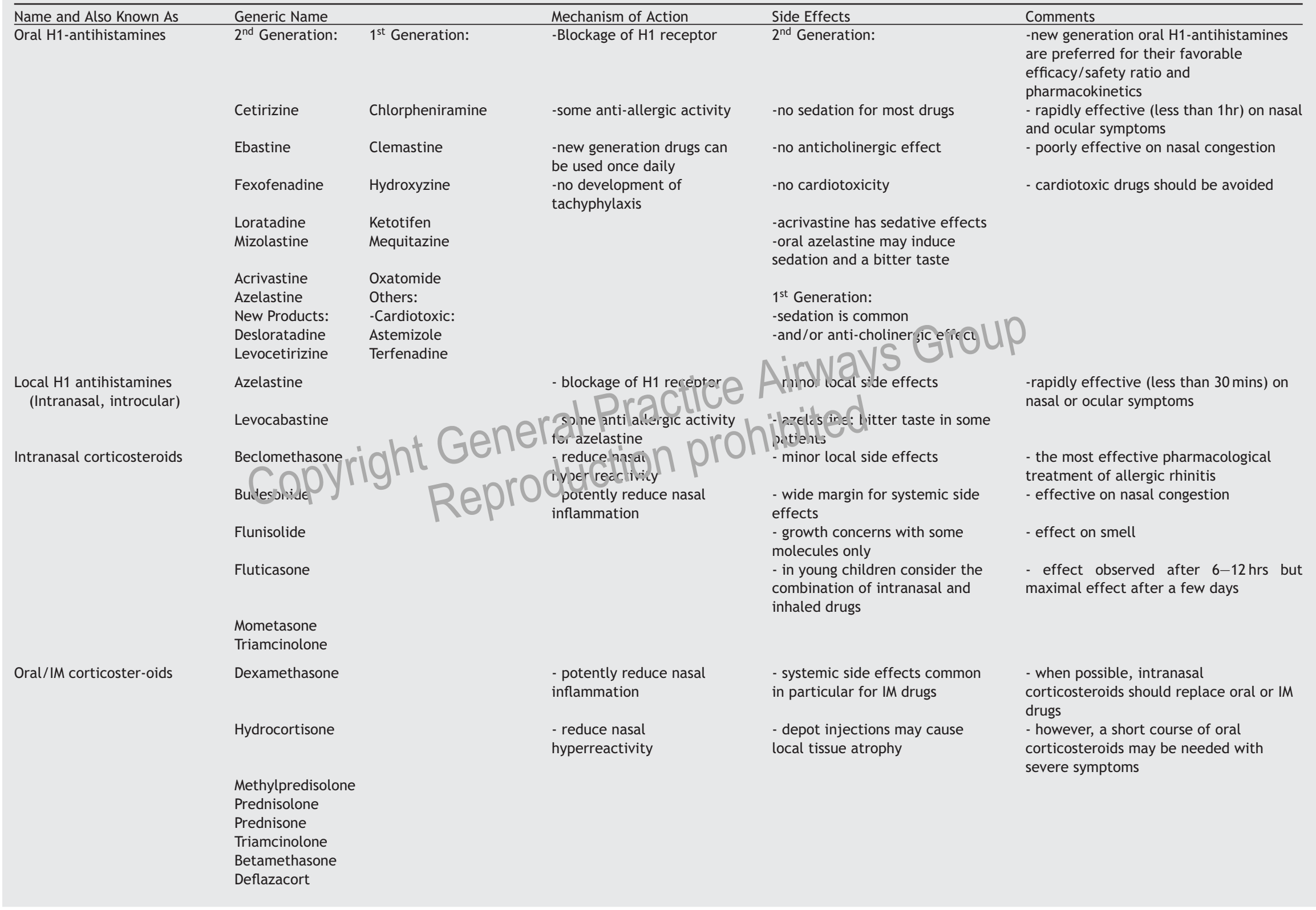




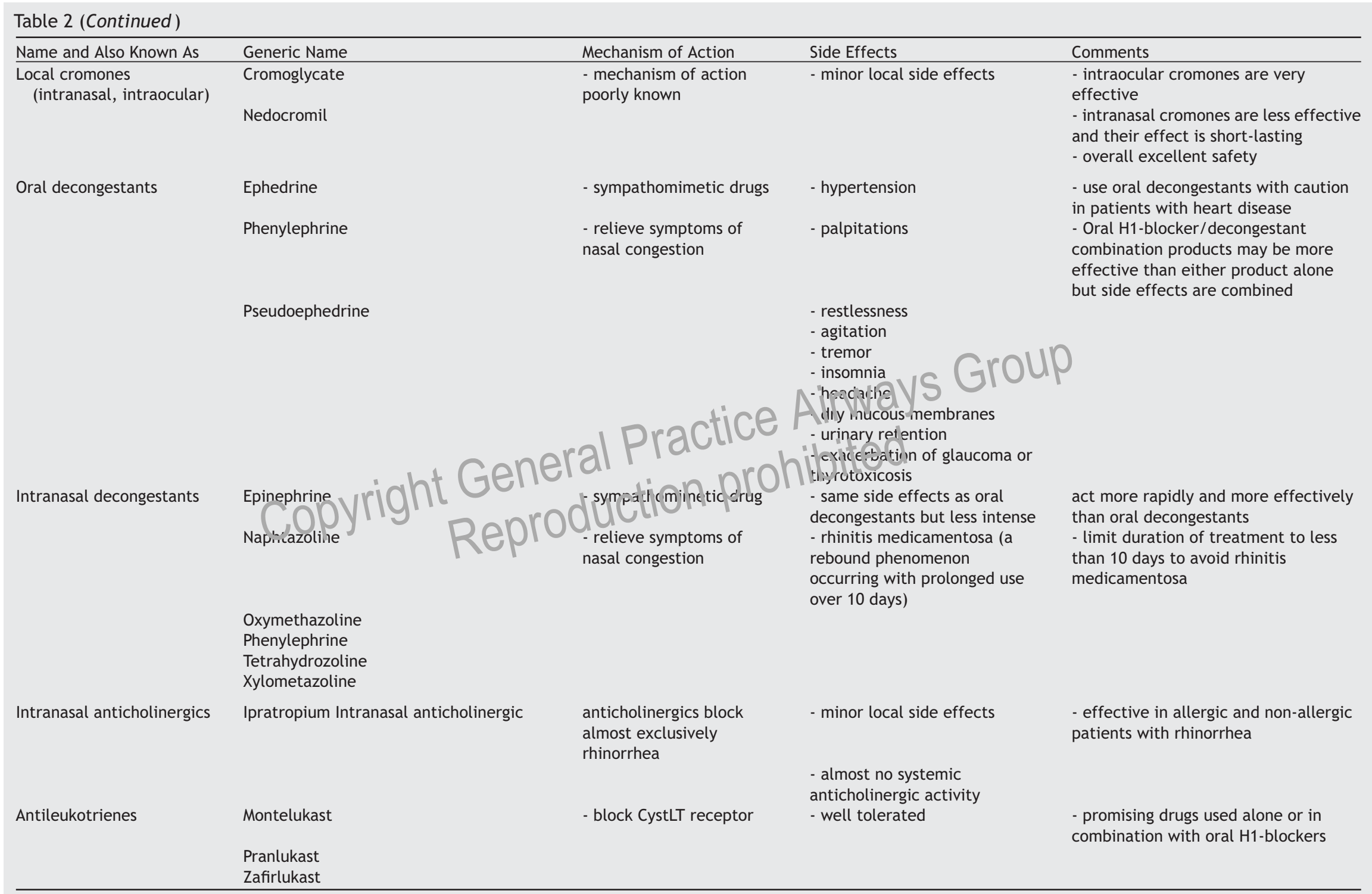




\section{Oral and local H1 antihistamines}

Both oral and topical (intranasal and ocular) antihistamine preparations are available for the treatment of allergic rhinitis. $\mathrm{H}_{1}$-blockers or $\mathrm{H}_{1}$ antihistamines are medications blocking histamine at the $\mathrm{H}_{1}$ receptor level (neutral antagonists or inverse agonists) [20]. Some also possess additional anti-allergic properties. During the last 20 years, pharmacological research has produced compounds with minimal sedative effect and impairment, the so-called second generation $\mathrm{H}_{1}$-antihistamines. Oral antihistamines are effective against symptoms mediated by histamine, including rhinorrhea, sneezing, nasal itching, and eye symptoms [21] ${ }^{* * *}$ but are less effective on nasal congestion $[22,23]^{* * *}$.

If administered, patients should be advised of the expected side effects (see Table 2) of first-generation oral $\mathrm{H} 1$-antihistamines including sedation and central nervous system impairment which can affect performance of cognitive and skilled tasks such as learning and driving [24] ${ }^{* * *}$. These impairments can be potentiated by alcohol and other sedative medications, and can worsen sleep disturbance due to rhinitis. Side-effects may not always be perceived by patients. Some, but not all, oral $\mathrm{H}_{1}$-antihistamines undergo hefais is metabolism via the cytochrome p150 gysten and may be prone to drug initeractions. Certain medications herbal oroducts, foods and dieterly supplenenc, can affect the bic divalastity of some second-generation ancihistamines. $\mathrm{H}_{1}$ antihistamines are approved for use in young children [25]. Major concerns exist about the arrhythmogenic action of terfenadine, astemizole, and high doses of diphenhydramine. This is not a class effect [22], and the use of terfenadine and astemisole is therefore not advised $[10]^{* * *}$.

$\mathrm{H}_{1}$-antihistamines given topically (intranasally or ocularly) are as effective as oral antihistamines at the site of their administration in reducing itching, sneezing, runny nose, and eye symptoms $[21,22,26]$. They can be effective within 20 minutes of administration [27] ${ }^{* * *}$. Topical $\mathrm{H}_{1}$-antihistamines require twice-a-day dosing. In general, topical antihistamines are well tolerated.

\section{Intranasal glucocorticosteroids}

Intranasal glucocorticosteroids are currently the most effective class of medications available for the treatment of allergic and non-allergic rhinitis [28]. The effectiveness of intranasal glucocorticosteroids is based on their local activity since administration of an equivalent amount of medication orally produces no benefit. The rationale for using intranasal glucocorticosteroids in the treatment of allergic rhinitis is that high medication concentrations can be achieved at receptor sites in the nasal mucosa with minimal risk of systemic adverse effects [10] ${ }^{* * *}$.

Glucocorticosteroids can suppress many stages of the allergic inflammatory process by interacting with transcription factors $[29,30]$. Due to their mechanism of action, efficacy appears after 7-8 hours of dosing, but maximum efficacy may require up to two weeks. Intranasal glucocorticosteroids have also been shown to improve quality of life, increase the patient's sense of well-being, improve performance at work and school, and reduce sleep problems associated with nasal congestion $[31,32]^{* \star *}$. They may also have a prophylactic effect when administered before the onset of the pollen season [33]". If nasal congestion is present, or symptoms are frequent, an intranasal glucocorticosteroid is the most effective treatment $[28,34,35]$. Previously, regular treatment was thought to be necessary. However, recent studies show that glucocorticosteroids administered on an/ Gs neecied (prn) basis have similar on beiter efficacy than oral $\mathrm{H}_{1}$ antibistamines on nalial symptoms, but that 'prn' use is less effectivel than continuous treatment [30 ] $]^{*}$.

In clinical studies, intranasal glucocorticosteroids are well tolerated, and adverse effects are few in number, mild in severity, and similar to placebo [37]. Crusting, dryness and minor epistaxis may occur in about $5 \%$ of patients and may be a reason for stopping treatment. Evidence shows that long-term use of intranasal glucocorticosteroids is free of the concerns associated with long-term use of oral glucocorticosteroids. Even with long-term use, newer intranasal glucocorticosteroids appear to have no effect on the hypothalamic-pituitaryadrenal axis and do not induce nasal mucosal atrophy [38-40]. In children, the rate of growth was slightly reduced in those regularly treated with beclomethasone over one year by the intranasal route [41]. The clinical significance of this reduced rate of growth is unknown. This effect does not appear to be a class effect since recent studies have shown normal growth rates in children treated with newer intranasal glucocorticosteroids [42]. However, it is reasonable to monitor the growth of children receiving long-term treatments with intranasal glucocorticosteroids.

The health care professional should advise patients on the proper method to administer 
intranasal glucocorticosteroids, including the importance of directing the spray laterally and not medially (towards the nasal septum).

\section{Systemic and intranasal glucocorticosteroids}

Oral glucocorticosteroids are rarely needed to control severe symptoms of allergic rhinitis. Although these medications are effective, they cause unacceptable systemic side effects if used for a prolonged period of time. A short course of oral corticosteroids (three to seven days) may be necessary for patients with severe symptoms or to gain control of symptom exacerbations. Intramuscular injection of glucocorticosteroids is not recommended by ARIA due to the possible occurrence of systemic side effects [10] . Intranasal injection of glucocorticosteroids is not usually recommended due to the possible occurrence of blindness $[10]^{* * *}$.

\section{Chromones}

Sodium cromoglycate and nedocromil have an excellent safety profile. They reduce the symptoms of allergic rhinitis, but limited efficacy and the need for frequent dosing (up to four times daily) are disadvantages. Chromones are general'y less effective than other medicanion. is the treatment of $a^{\prime \prime l}$ egif ifhinitis $[10]^{* * *}$. Oculat sodium clomos, (veate or nedecromilareftecive and have a place in the treatme ic of allergic conjunctivitis [26] $]^{* * *}$. Single-dose formulations without preservatives are often better tolerated by the patients.

\section{Decongestants}

Short courses (less than 10 days) of topical decongestants may be useful in reducing severe nasal blockage when starting administration of other medications. Both oral and intranasal decongestants may be used in the treatment of nasal congestion associated with allergic rhinitis. Nasal decongestant sprays have a greater effect on nasal obstruction than oral decongestants. However, the use of nasal decongestant sprays is limited by rebound congestion, the potential for irreversible tissue hypertrophy [43] $]^{* * *}$, and a decreasing duration of effect after 10 days of use $[44]^{* * *}$. Rhinitis medicamentosa constitutes nasal hyper-reactivity, mucosal swelling, and tolerance, that is induced, or aggravated, by the overuse of topical decongestants with or without a preservative.
Attention should be paid to a range of possible contraindications and warnings associated with oral decongestants, including use in elderly patients, patients suffering from hypertension, hyperthyroidism, prostatic hypertrophy, glaucoma, and psychiatric disorders, and in patients taking beta-blockers and monoamine oxidase inhibitors $[10]^{* * *}$.

\section{Anticholinergics}

Anticholinergic agents can help reduce anterior watery rhinorrhea but they have no effect on nasal blockage or the other symptoms of allergic rhinitis $[10]^{* * *}$.

\section{Antileukotrienes}

Antileukotrienes are a new class of medication for the treatment of allergic rhinitis as well as asthma and have been shown to be effective in improving both asthma and rhinitis outcomes [45] ${ }^{* * *}$. They modulate inflammation. They have an efficacy comparable to that of oral antihistamines although appear to have a greater effect on nasal ( Dstruction [46]". Antileukotrienes may häve an daditive effect with antihistarlines: [1], 83].

\section{Allergen-specific innunotherapy (vaccination)}

Allergen-specific vaccination is the practice of administering gradually increasing quantities of an allergen extract to an allergic subject in order to ameliorate the symptoms associated with subsequent exposure to the causative allergen. The efficacy of immunotherapy using inhalant allergens to treat allergic rhinitis and asthma is evidence-based when optimally administered $[10,49]^{* * *}$. Standardised therapeutic vaccines which are available for the most common allergens are favoured. Adequate courses of therapy (three to four years) may induce prolonged remission of symptoms. Treatment is recommended for patients with evidence of clinically relevant IgE-mediated disease and a limited spectrum of allergies, in whom pharmacotherapy and avoidance measures provide inadequate control [10].

Subcutaneous immunotherapy should be performed by trained personnel supervised by a physician, and patients should be monitored for 30 minutes after injection. Medications and equipment for treatment of rare but potentially life-threatening acute allergic reactions triggered by subcutaneous immunotherapy should be available. 
Allergen-specific immunotherapy interferes with the basic mechanisms of allergy and alters the natural course of allergic diseases, resulting in symptomatic relief and offering the patient a long-lasting and preventive effect; it is currently recommended for those patients with moderate to severe disease especially if not responsive to other therapy [10]. Treatment benefits are observed both using subcutaneous [50] and sublingual routes [51]. Subcutaneous immunotherapy has been shown to reduce the onset of new sensitisations [52] as well as the development of asthma in patients with allergic rhinitis [53].

\section{Alternative therapies}

The use of complementary and alternative therapies (e.g. homeopathy, herbal medicines, acupuncture) for the treatment of rhinitis is increasing. In the ARIA document [10], a literature review found insufficient evidence to support the efficacy of alternative therapy. Since then there have been further publications, but the design of the trials or the outcome measures used make it impossible to reach a definitive conclusion regarding their use in the management of allergic rhinitis." A recent Cochrane Review concluded triat there was insufficient evidenre to assess deliably the role of homeopathy in as thi] a [34]. There is an

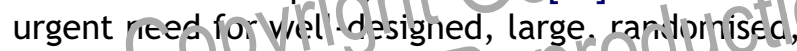
controlled ano properly-poiverey clinicai trials to evaluate the efficacy and safety of alternative therapies in the management of allergic diseases.

Herbal medicine can induce pharmacologic interactions with medications used in the treatment of allergic rhinitis or other illnesses [55]. Healthcare professionals should ask their patients about the use of herbal products and consider the possibility of herb-drug interactions [56].

\section{Route of administration}

Medications for allergic rhinitis are most commonly given either intranasally or orally. The advantage of intranasal administration, particularly of glucocorticosteroids, is that high local concentrations of the drug can be achieved with minimal systemic side effects [57] ${ }^{* * *}$. The health care professional should advise patients on the proper method to administer intranasal glucocorticosteroids, including the importance of directing the spray laterally rather than medially in the nose, using the left hand for the right side of the nose and vice versa.

\section{Management of ocular symptoms}

Intranasal glucocorticosteroids have been shown to have some effect on the eye symptoms associated with allergic rhinitis $[58,59,60]^{* * *}$. Intraocular glucocorticosteroids are effective, but because of known side effects should be avoided or should only be prescribed and monitored by eye specialists. The use of antihistamine or cromone eye drops is justified if ocular symptoms are the predominant and/or persistent feature of the patient's allergic rhinitis despite use of oral $\mathrm{H} 1$-antihistamines and/or intranasal glucocorticosteroids. Cold compresses are effective for mild to moderate ocular symptoms, and topical non-steroidal anti-inflammatory drugs (NSAIDs) relieve itching.

\section{Management of co-existing allergic rhinitis and asthma}

Allergic rhinitis and asthma often co-exist: at least $75 \%$ of patients with asthma complain of rhinitis symptoms, and $20-30 \%$ of thos $=$ vich allergic rhinitis also have as h ne [61,62]. Allergic rhinitis is aisca 1s'k factor for developing asthma [63]. necent evidence sug jests that patients with coexisting onlsiciar diagnosed asthma and rhinitis ha worse asthma outcomes than those with physician-diagnosed asthma only [64,65]. Thus, patients with asthma should be assessed for symptoms and signs of rhinitis and vice versa.

Some medications (e.g., glucocorticosteroids and antileukotrienes) are effective against both allergic rhinitis and asthma symptoms. Patients with both allergic rhinitis and asthma may be prescribed both intranasal and inhaled glucocorticosteroids if appropriate to the severity of their disease, although attention should be paid to the total dose of glucocorticosteroids, particularly in children. Optimal management of rhinitis may improve co-existing asthma and failure to treat rhinitis adequately in those with asthma may make asthma more difficult to control.

\section{Management of allergic rhinitis during pregnancy}

Rhinitis is often a problem during pregnancy, since it can cause exacerbation of nasal obstruction. Caution must be used when administering rhinitis medication during pregnancy because of placental transfer, although in asthmatic patients the benefits 
of treating asthma outweigh any potential risks to the fetus from inhaled steroids. Few studies on the use of allergic rhinitis medications during pregnancy have been conducted.

\section{Follow-up and Ongoing Care}

Patients should be reviewed two to four weeks after initiation of therapy. In general, if patients show improvement then the medication dose should be stepped down if possible. When treating persistent rhinitis, patients should continue treatment for at least one month after resolution of symptoms.

If patients fail to respond to initial therapy, it is essential to review compliance and reconsider the diagnosis, querying infections and other potential causes of symptoms. If there is confidence about the diagnosis, a one-month trial of an alternative therapy is indicated.

\section{Access to professional advice}

Many of the treatments referred to in this paper can be accessed 'over the counter' without a prescription from a pharmacy, and some cin be obtained from any retail outia?. Ine exact level of access varies acrss clifierent countries In many countries the role of thercornunity pharmacist is becoming more cirine? and patientfocused, and ARIA have produced specific guidelines for pharmacists to use when advising patients who seek advice regarding the symptoms of rhinitis [66].

\section{Referral}

Referral should be considered for any patient who shows persistent failure to respond to the therapeutic options for their classification of rhinitis or whose symptoms are suggestive of other conditions (see Allergic Rhinitis Diagnosis Questionnaire, Tables 3 and 4 in the IPCRG Guidelines: Diagnosis [2]).

\section{Conclusions and recommendations}

Rhinitis is an important condition both in its own right and because of its impact on asthma. The aim of treatment should be to ensure as full a quality of life as possible for patients with rhinitis based on education and allergen avoidance, pharmacotherapy, specific immunotherapy and rarely surgery. For patients with both asthma and rhinitis there should be a combined approach to treatment, thereby ensuring best possible control of both conditions.

\section{Potential conflicts of interest}

David Price has no shares in pharmaceutical companies. He has received speaker's honoraria for speaking at sponsored meetings from the following companies marketing respiratory products: $3 \mathrm{M}$, Altana, Astra Zeneca, BI, GSK, MSD, Novartis, Pfizer, Schering-Plough. He has received honoraria for advisory panels with; $3 \mathrm{M}$, Altana, Astra Zeneca, BI, GSK, MSD, Novartis, Pfizer, Schering-Plough, UCB. $\mathrm{He}$ or his research team have received funding for research projects from: 3M, Altana, Astra Zeneca, BI, GSK, MSD, Novartis, Pfizer, Schering-Plough, Viatris.

Christine Bond has been an adviser to GlaxoSmithKline and Altana Pharma.

Jacques Bouchard is on the PCWG advisory board for GlaxoSmithKline, a member of the advisory board on COPD for Pfizer and Buehringer Ingelheim, and Altana Phacina (Astima).

Rui Costi has tiesen an independent invited speckerer tor Pfizer, Boehringer Ingelheim, Novartis, Merck Sharp \& pointe. and Schering Plough on more than crie cccasion.

Jcseph Keenan is on a primary care advisory group for GlaxoSmithKline, and he is a speaker for GlaxoSmithKline, Pfizer, Boehringer Ingelheim, Schering Plough and Pharmacia Diagnostics.

Mark Levy has no shares in pharmaceutical companies. He has received speaker's honoraria for speaking at sponsored meetings from the following companies marketing respiratory products: IVAX, Astra Zeneca, BI, GSK, MSD and Schering-Plough. He has received honoraria for advisory panels with; Trinity Cheisi, 3M, Altana, Astra Zeneca, BI, GSK, MSD, Novartis, Schering-Plough. He has received funding for research projects from: $3 M$, Astra Zeneca, GSK, Schering-Plough, Viatris. He has accepted sponsorship to attend conferences from: $3 \mathrm{M}$, Altana, Astra Zeneca, BI, GSK, MSD, Novartis, Schering-Plough, Viatris, Innovata Biomedica and Trinity Cheisi.

Maria Orru on one occasion was an independent invited speaker for Pfizer.

Dermot Ryan has received consultancy fees from, lectured for, or received subsidies to attend meetings for: GlaxoSmithKline, AstraZeneca, 3M Rhone Poulenc Rorer, Schwartz, Altana Pharma, Novartis, Merck Sharp \& Dohme, Ivax, Trinity-Chiesi and Schering Plough. 
Samantha Walker has received honoraria for consultancy, lectures and publications from GlaxoSmithKline, UCB, Pharmacia UK, Schering Plough UK and Pfizer UK.

Margaret Watson has no conflict of interest.

\section{Acknowledgements}

The authors would like to thank S Conn, J Leder, S Louw, and M Stubbe Østergaard who contributed to earlier versions of this document.

Funding: During the development of these guidelines, the IPCRG received unrestricted educational grants from Altana, AstraZeneca, Boehringer Ingelheim, EAMG, GlaxoSmithKline, Merck Sharp and Dohme, Mitsubishi Pharma, Novartis, UCB Pharma, and Zambon. These funds were used for the purpose of funding face-to-face meetings and also to support a secretariat.

\section{References}

[1] International Primary Care Airways Group (IPAG). Chronic airways diseases: a guide for primary care physicians. Available at the URL http://www.ipagguide.org/In: $G$ copyright_draft.pdf.

[2] Levy ML, Actcher M, Price DB, lausen B, Putelt RJ, Yawn BP. International Primar. Cire Respiratory Group (IPCRG

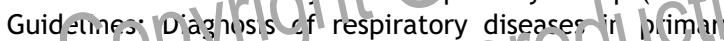
care. Princ ue ßesp J 2006;10(1) $201-31$

[3] Bellamy D, Bouchard J, $H \in$ nrichisen $S$, Johansson G, Langhammer A, Reid J, van Weel C, Buist S. International Primary Care Respiratory Group (IPCRG) Guidelines: Management of chronic obstructive pulmonary disease (COPD). Prim Care Resp J 2006;15(1):48-57.

[4] van der Molen T, Østrem A, Stallberg B, Stubbe Østergaard $M$, Singh RB. International Primary Care Respiratory Group (IPCRG) Guidelines: Management of asthma. Prim Care Resp J 2006;15(1):35-47.

[5] Royal College of General Practitioners. The development and implementation of clinical guidelines. Report of the clinical guidelines working group. London, 1995. RCGP.

[6] Blackley $\mathrm{CH}$. Experimental researches on the causes and nature of Catarrhus Aestivus (Hay-fever or Hay-asthma). London: Balliere, Tindall \& Cox; 1873.

[7] Asthma in adults and schoolchildren. The General Practioner in Asthma Group, the British Association of Accident and Emergency Medicine, the British Paediatric Respiratory Society and the Royal College of Paediatrics and Child Health. Thorax 1997;52(Suppl 1):S2-8, S11-5, S20-1.

[8] British guideline on the management of asthma. (2003) Thorax, 58 Suppl 1, Pages 1-94. BTS/SIGN. Available at URL http://www.sign.ac.uk/guidelines/fulltext/63/index.html.

[9] Global Strategy for Asthma Management and Prevention. NIH Publication No 02-3659 Issued January, 1995 (updated 2002) Management Segment (Chapter 7): Updated 2005 from the 2004 document. The GINA reports are available at URL http: //www.ginasthma.org.
[10] Bousquet J, Van Cauwenberge PB, Khaltaev N. Allergic Rhinitis and its Impact on Asthma (ARIA) in collaboration with the World Health Organization (WHO). J Allergy Clin Immunol 2001;108:S147-336. See also Pocket Guide at URL http://www.whiar.com.

[11] Leynaert B, Bousquet J, Neukirch C, et al. Perennial rhinitis: An independent risk factor for asthma in nonatopic subjects: Results from the European Community Respiratory Health Survey. J Allergy Clin Immunol 1999;104:301-4.

[12] The International Study of Asthma and Allergies in Childhood (ISAAC) Steering Committee. Worldwide variation in prevalence of symptoms of asthma, allergic rhinoconjunctivitis, and atopic eczema: ISAAC. Lancet 1998;351:1225-32.

[13] Gaga M, Lambrou P, Papageorgious N, et al. Eosinophils are a feature of upper and lower airway pathology in non-atopic asthma, irrespective of the presence of rhinitis. Clin Exp Allergy 2000;20:663-9.

[14] Corren J, Adinoff AD, Irvin CG. Changes in bronchial responsiveness following nasal provocation with allergen. J Allergy Clin Immunol 1992;89:611-8.

[15] Braunstahl G-J, Kleinjan A, Overbeek SE, et al. Segmental bronchial provocation induces nasal inflammation in allergic rhinitis patients. Am J Respir Crit Care Med 2000;161:2051-7.

[16] Thomas M, Kocevar VS, Zhang Q, Yin DD, Price D. Asthmarelated health care resource use among asthmatic children with and without concomitant allergic rhinitis. Pediatrics 2005;115:129-34.

[17] Price D, Zhang Q, Kocevar VS, ir oD, th ornas M. Effect of a concomitant diogn bsis or al ergic rhinitis on asthmarelated tieal t 1 -are 1 . e by adults. Clin Exp Allergy 2005;35: 28: 7 .

[18] Sheikh A, Hiryitzo B. House dust mite avoidance mexs es fo- hurennal allergic rhinitis. [Review] [16 - if 1 Cocnrane Database of Systematic Reviews 2001;(4): CD001563.

[19] Bemt L, van Knapen $L$, de Vries $M P$, Jansen $M$, Cloosterman S, van Schayck CP. Clinical effectivenss of a mite-allergen impermeable bed covering system in asthmatic mite-sensitive patients. J Allergy Clin Immunol 2004;114(4):858-62.

[20] Leurs R, Church MK, Taglialatela M. H1-antihistamines: inverse agonism, anti-inflammatory actions and cardiac effects. [Review] [103 refs]. Clin Exp Allergy 2002;32: 489-98.

[21] Howarth P. Antihistamines in rhinoconjunctivitis. [Review] [225 refs]. Clin Allergy Immunol 2002;17:179-220.

[22] Passalacqua G, Canonica GW, Bousquet J. Structure and classification of $\mathrm{H} 1$-antihistamines and overview of their activities. [Review] [320 refs]. Clin Allergy Immunol 2002;17:65-100.

[23] Nielsen LP, Mygind N, Dahl R. Intranasal corticosteroids for allergic rhinitis: superior relief? [Review] [200 refs]. Drugs 2001;61(11):1563-79.

[24] Milgrom H, Bender B, Wamboldt F. Of injuries and antihistamines and dosing. [comment]. Ann Allergy Asthma Immunol 2002;89(3):221-3.

[25] Simons FE. H1-antihistamines in children. [Review] [120 refs]. Clin Allergy Immunol 2002;17:437-64.

[26] Friedlaender $M$. Overview of ocular allergy treatment. [Review] [22 refs]. Curr Allergy Asthma Reports 2001;1(4): 375-9.

[27] Noble S, McTavish D, Levocabastine. An update of its pharmacology, clincial efficacy an tolerability in the topical treatment of allergic rhinitis and conjunctivitis. Drugs 1995;50(6):1032-49. 
[28] Weiner JM, Abramson MJ, Puy RM. Intranasal corticosteroids versus oral $\mathrm{H} 1$ receptor antagonists in allergic rhinitis: systematic review of randomised controlled trials. BMJ 1998;317(7173):1624-9.

[29] Fokkens WJ, Godthelp T, Holm AF, Klein-Jan A. Local corticosteroid treatment: the effect on cells and cytokines in nasal allergic inflammation. [Review] [57 refs]. Am J Rhinol 1998;12(1):21-6.

[30] Adcock IM, Caramori G. Cross-talk between proinflammatory transcription factors and glucocorticoids. [Review] [52 refs]. Immunol Cell Biol 2001;79(4):376-84.

[31] Brogden RN, McTavish D. Budesonide. An updated review of its pharmacological properties, and therapeutic efficacy in asthma and rhinitis. Drugs 1992;44(3):375-407.

[32] Ratner PH, Paull BR, Findlay SR, Hampel Jr F, Martin B, Kral $\mathrm{KM}$, et al. Fluticasone propionate given once daily is as effective for seasonal allergic rhinitis as beclomethasone dipropionate given twice daily. J Allergy Clin Immunol 1992;90(3:Pt 1):285-91.

[33] Graft D, Aaronson D, Chervinsky P, Kaiser H, Melamed $\mathrm{J}$, Pedinoff A, et al. A placebo- and active-controlled randomized trial of prophylactic treatment of seasonal allergic rhinitis with mometasone furoate aqueous nasal spray. J Allergy Clin Immunol 1996;98:724-31.

[34] Craig TJ, Teets S, Lehman EB, Chinchilli VM, Zwillich C. Nasal congestion secondary to allergic rhinitis as a cause of sleep disturbance and daytime fatigue and the response to topical nasal corticosteroids. J Allergy Clin Immunol 1998;101:633-7.

[35] Bousquet J, Chanal I, Alquie MC, Charpin D, Didier A, Germouty J, et al. Prevention of pollen rhinitis symptoms: comparison of fluticasone propionate aqueous nasal spray and disodium cromoglycate aqueous nasal spray A multicenter, double-blind, double-dummy, paralle- gro p study. Allergy 1993;48:327-33.

[36] Kaszuba SM, Baroody FM a ineo T1, Haney L, Blair C Nacleri $2 M$. Buplior $t$, of an intranasal corticostie orc compared wi th an oral antihis aritic in the ac nceded treatment of seasonal allergic rhinitis. Arch Inter Med 2001;161:2581-7.

[37] Meltzer EO, Orgel HA, Bronsky EA, Furukawa CT, Grossman $\mathrm{J}$, LaForce $\mathrm{CF}$, et al. A dose-ranging study of fluticasone propionate aqueous nasal spray for seasonal allergic rhinitis assessed by symptoms, rhinomanometry, and nasal cytology. J Allergy Clin Immunol 1990;86:221-30.

[38] Holm AF, Fokkens WJ, Godthelp T, Mulder PG, Vroom TM, Rijntjes E. A 1-year placebo-controlled study of intranasal fluticasone propionate aqueous nasal spray in patients with perennial allergic rhinitis: a safety and biopsy study. Clin Otolaryngol Allied Scienc 1998;23:69-73.

[39] Laliberte F, Laliberte MF, Lecart S, Bousquet J, Klossec $J M$, Mounedji N. Clinical and pathologic methods to assess the long-term safety of nasal corticosteroids. French Triamcinolone Acetonide Study Group. Allergy 2000;55:718-22.

[40] Minshall E, Ghaffar O, Cameron L, O’Brien F, Quinn H, RoweJones $\mathrm{J}$, et al. Assessment by nasal biopsy of long-term use of mometasone furoate aqueous nasal spray (Nasonex) in the treatment of perennial rhinitis. Otolaryngol Head Neck Surg 1998;118:648-54.

[41] Skoner DP, Rachelefsky GS, Meltzer EO, Chervinsky P, Morris RM, Seltzer JM, et al. Detection of growth suppression in children during treatment with intranasal beclomethasone dipropionate. Pediatrics 2000;105:E23.

[42] Schenkel EJ, Skoner DP, Bronsky EA, Miller SD, Pearlman DS, Rooklin A, et al. Absence of growth retardation in children with perennial allergic rhinitis after one year of treatment with mometasone furoate aqueous nasal spray. Pediatrics 2000;105:E22.

[43] Graf P. Rhinitis medicamentosa: aspects of pathophysiology and treatment. Allergy 1997;52(40:Suppl):Suppl-34.

[44] Graf P, Enerdal J, Hallen H. Ten days' use of oxymetazoline nasal spray with or without benzalkonium chloride in patients with vasomotor rhinitis. Arch Otolaryngol Head Neck Surg 1999;125:1128-32.

[45] Philip GP, Nayak AS, Berger WE, et al. The effect of montelukast on rhinitis symptoms in patients with asthma and seasonal allergic rhinitis. Curr Med Res Opin 2004;20:1549-58.

[46] Meltzer EO, Malmstrom K, Lu S, Prenner BM, Wei LX, Weinstein SF, et al. Concomitant montelukast and loratadine as treatment for seasonal allergic rhinitis: a randomized, placebo-controlled clinical trial. J Allergy Clin Immunol 2000;105:917-22.

[47] Ciprandi G, Tosca MA, Milanese M, Schenone G, Ricca $\mathrm{V}$. Antihistamines added to an antileukotriene in treating seasonal allergic rhinitis: histamine and leukotriene antagonism. Allergy Immunol 2004;36:67-70.

[48] Kurowski M, Kuna P, Gorski P. Montelukast plus cetirizine in the prophylactic treatment of seasonal allergic rhinitis: influence on clinical symptoms and nasal allergic inflammation. Allergy 2004;59:280-8.

[49] Abramson M, Puy R, Weiner J. Immunotherapy in asthma: an updated systematic review. [Review] [205 refs]. Allergy 1999;54:1022-41.

[50] Durham SR, Walker SM, Varga EM, Jacobson MR, O'Brien F, Noble $W$, et al. Long-term clinic al efii a: 6 orass-pollen immunotherapy. New Engl J Aned 19) $4 ; 341: 468-75$.

[51] Di RV, Mar :i'Cl: H l Pu crinell P, Parmiani S, Frati F, Sensi t $t$ et at Lons-lasting effect of sublingual immunotherapy in children with "at thim flue to house dust mite: a 10-year prosnest ve ; U(1): ( clin Exp Allergy 2003;33:206-10.

[0.] Le RA, Paradis L, Menardo JL, Bouges S, Daures JP, Bousquet J. Immunotherapy with a standardized Dermatophagoides pteronyssinus extract. VI. Specific immunotherapy prevents the onset of new sensitizations in children. J Allergy Clin Immunol 1997;99:450-3.

[53] Moller C, Dreborg S, Ferdousi HA, Halken S, Host $A$, Jacobsen $L$, et al. Pollen immunotherapy reduces the development of asthma in children with seasonal rhinoconjunctivitis (the PAT-study). J Allergy Clin Immunol 2002;109:251-6.

[54] Linde K, Jobst KA. Homeopathy for chronic asthma. Cochrane Database of Systematic Reviews 2000;(2): CD000353.

[55] Izzo AA, Ernst E. Interactions between herbal medicines and prescribed drugs: a systematic review. Drugs 2001;61:2163-75.

[56] Chanez P, Vignola AM, Vic P, Guddo F, Bonsignore G, Godard P, et al. Comparison between nasal and bronchial inflammation in asthmatic and control subjects. Am J Respir Critic Care Med 1999;159:588-95.

[57] Bousquet J, Van Cauwenberge P, Bachert C, et al., European Academy of Allergy and Clinical Immunology (EAACl); Allergic Rhinitis and its Impact on Asthma (ARIA). Requirements for medications commonly used in the treatment of allergic rhinitis. European Academy of Allergy and Clinical Immunology (EAACl), Allergic Rhinitis and its Impact on Asthma (ARIA). Allergy 2003;58: 192-7.

[58] Weiner JM, Abramson MJ, Puy RM. Intranasal corticosteroids versus oral $\mathrm{H} 1$ receptor antagonists in allergic rhinitis: systematic review of randomised controlled trials.[comment]. BMJ 1998;317:1624-9. 
[59] Lanier BQ, Abelson MB, Berger WE, et al. Comparison of the efficacy of combined fluticasone propionate and olopatadine versus combined fluticasone propionate and fexofenadine for the treatment of allergic rhinoconjunctivitis induced by conjunctival allergen challenge. Clin Ther 2002;24:1161-74.

[60] Spangler DL, Abelson MB, Ober A, Gotnes PJ. Randomized, double-masked comparison of olopatadine ophthalmic solution, mometasone furoate monohydrate nasal spray, and fexofenadine hydrochloride tablets using the conjunctival and nasal allergen challenge models. Clin Ther 2003;25:2245-67.

[61] Leynaert B, Bousquet J, Neukirch C, et al. Perennial rhinitis: An independent risk factor for asthma in nonatopic subjects: Results from the European Community Respiratory Health Survey. J Allergy Clin Immunol 1999;104:301-4.

[62] The International Study of Asthma and Allergies in Childhood (ISAAC) Steering Committee. Worldwide variation in prevalence of symptoms of asthma, allergic rhinoconjunctivitis, and atopic eczema: ISAAC. Lancet 1998;351:1225-32.

[63] Wright AL, Holberg CJ, Martinez FD, Halonen M, Morgan W, Taussig LM. Epidemiology of physician-diagnosed allergic rhinitis in childhood. Pediatrics 1994;94:901.

[64] Price D, Zhang Q, Kocevar VS, Yin DD, Thomas M. Effect of a concomitant diagnosis of allergic rhinitis on asthma-related health care use by adults. Clin Exp Allergy 2005;35:282-7.

[65] Thomas M, Kocevar VS, Zhang Q, Yin DD, Price D. Asthmarelated health care resource use among asthmatic children with and without concomitant allergic rhinitis. Pediatrics 2005;115:129-34.

[66] Bousquet J, van Cauwenberge P, Khaltaev N, et al. ARIA in the pharmacy: management of allergic rhinitis symptoms in the pharmacy. Allergic rhinitis and its impact on asthma. Allergy 2004;59:373-87.

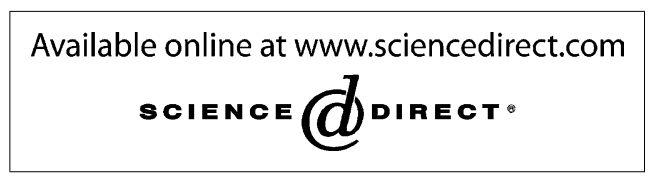

\section{Available online at http://www.thepcrj.com}

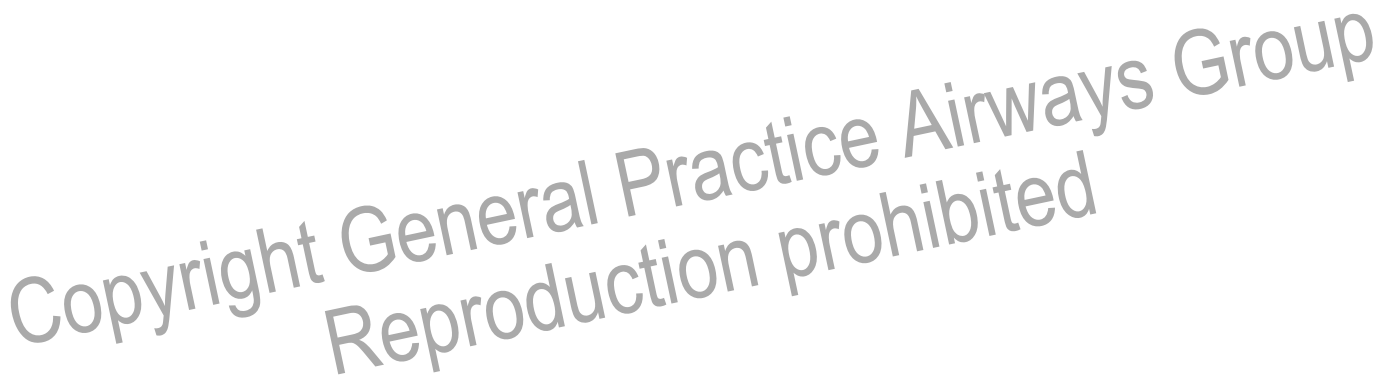

